\title{
Feasibility and safety of 2-week protocol biopsy after kidney transplantation
}

\author{
Manuel Lim¹, Kyo Won Lee ${ }^{1}$, Byung Kwan Park², Jae Berm Park , Sang Jin Kim, Kyeong-Deok Kim¹, Okjoo Lee, Jaehun \\ Yang $^{1}$, Jieun Kwon ${ }^{1}$, Eun sung Jung ${ }^{1}$
}

${ }^{1}$ Division of Transplantation, Department of Surgery, Samsung Medical Center, Seoul, Korea

${ }^{2}$ Department of Radiology, Samsung Medical Center, Seoul, Korea

Background: Protocol biopsies to detect and treat subclinical rejection early after kidney transplantation are useful for improving outcomes. However, there have been few studies on the optimal timing of early protocol biopsy. In this study, the results of 2-week and 1-year biopsies were analyzed in terms of technical feasibility, complications, and outcomes.

Methods: Allograft protocol biopsies were performed in 916 adult recipients of kidney transplantation between 2012 and 2019 in our center. Retrospective analysis of complications and clinical outcomes of 880 2-week biopsies and 556 1-year biopsies were performed.

Results: There were no significant difference between the median number of biopsy cores and sampled glomeruli of 2-week biopsies and 1-year biopsies. All allograft biopsies were technically successful. Total complication rates of 2-week and 1-year biopsies were $27.5 \%$ (242/880) and 15.5\% (86/556). Major complication (Clavien-Dindo grading III-IV) rates of 2-week and 1-year biopsies were $0.23 \%(2 / 880)$ and $0.18 \%(1 / 556)$. There were only two major complication cases in 2-week biopsies: bleeding requiring surgical exploration $(n=1)$ and bleeding requiring radiological intervention $(n=1)$, and was only one major complication case in 1-year biopsies: allograft failure $(n=1)$. There was no significant risk factor for major complication, even though immunologic factors, pre-biopsy laboratory results, basic characteristics are analyzed with univariate and multivariate analysis. Detection rates of subclinical rejection was 16.5\% (145/880) for 2-week biopsies and 32.9\% (183/556) for 1-year biopsies.

Conclusions: The 2-week protocol biopsy is as feasible and safe as the 1-year protocol biopsy in kidney transplant. It contributes to early detection of a significant number of subclinical rejection after kidney transplantation.

Corresponding author: Manuel Lim

E-mail: ykcywbd@gmail.com

(c) The Korean Society for Transplantation

This is an Open Access article distributed under the terms of the Creative Commons Attribution Non-Commercial License (http://creativecommons.org/licenses/by-nc/4.0/) which permits unrestricted non-commercial use, distribution, and reproduction in any medium, provided the original work is properly cited. 